\title{
TIPOGRAFIA: PANORAMA EVOLUTIVO HISTÓRICO E TECNOLÓGICO.
}

Typography: an evolutive historical and technological overview

\author{
Alessandro Ferreira Costa \\ Deborah Pereira Alves \\ Gabriela Reis Chaves Martins \\ Ivone Gomes da Silva \\ Thaís Mendes Gomes
}

\begin{abstract}
Resumo
Este artigo estabelece panorama sobre a evolução técnica dos processos de composição e impressão de textos em larga escala, que influenciaram o desenvolvimento da tipografia ao longo da história. Ressalta a importância da tipografia como veículo de transmissão de mensagens, configurando-se como meio de comunicação e acesso ao mundo das idéias. Esta breve revisão de literatura objetiva disseminar o tema, ampliando acesso a informação e de interfaces possíveis ao assunto tratado.
\end{abstract}

Palavras-chave: Tipografia. História. Tecnologia. Comunicação. Informação.

\begin{abstract}
This article establishes a general overview of the technical evolution of composition and large scale text printing process that influenced the typography's development through the history. It emphasizes typography's importance as a written message transmission vehicle, being a way of communication and access to the world of ideas. This brief literature review aims to disseminate its topic of discussion, enlarging the access to information and to this subject's possible interfaces.
\end{abstract}

Keywords: Typography. History. Technology. Communication. Information. 


\section{Introdução}

Assim como muitas outras áreas do saber, a tipografia, nas últimas décadas, parece atravessar um momento de revisão de valores e redefinição de território.(FARIAS, 2001, p.13)

Enquanto linguagem visual, a tipografia estabelece o inter-relacionamento usuário-informação, dialogando arte e design, produção e tecnologia, em um processo de transformações contínuo ditado pelo tempo e por suas raízes sócio-culturais. Enquanto estratégia de comunicação, aproxima o leitor de um dado produto/veículo do conjunto de significações registrado em uma mensagem, independente de sua natureza ou propósito, favorecendo o exercício da leitura sem com isto negligenciar aspectos estéticos formais presentes na forma de suas linhas.

Em um mundo saturado de mensagens, por vezes incompreendidas e, até mesmo, imperceptíveis, a tipografia exerce difícil tarefa de despertar e conduzir a atenção do leitor/receptor simultaneamente ao fato de não se tornar objeto principal desse olhar, favorecendo o fluxo e entendimento de um dado conteúdo (BRINGHURST, 2005), reforçando a idéia de Mike Baxter (1998) de que cada tipo de produto deve ter uma aparência visual adequada à sua função. Como cita Lucy Niemeyer (2000, p.11), só "será percebida, compreendida e utilizada a informação que se apresentar a seu destinatário de modo adequado e eficiente". Ressaltamos, porém, como cita Wolfgang Weingart, que a tipografia é também capaz de transcender a função primária de simples descritor de mensagens e tornar-se, por si só, a mensagem, de acordo com as atribuições a ela conferidas ou contexto em que se insere (apud PERROTA, 2005), evidenciando os valores visuais que compõem seu estilo.

Mas, enfim, o que é tipografia? Quais são suas potencialidades e dimensões de impacto ao longo de sua trajetória histórica e tecnológica enquanto meio de comunicação e informação? 


\title{
Tipo... grafando
}

Conceitualmente, podemos definir tipografia como

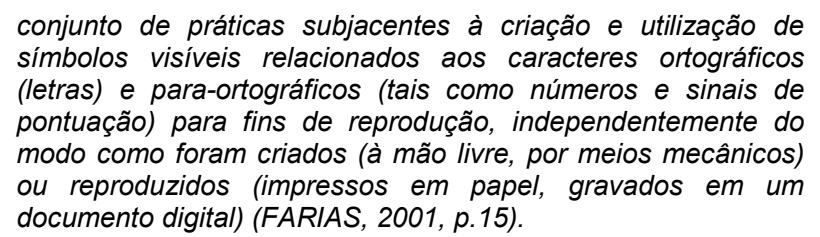

Ainda, de maneira complementar:

\begin{abstract}
É um conjunto de signos de função notacional, cujo significante não é a palavra (semema, morfema ou fonema), mas o desenho das letras do alfabeto (GRUSZYNSKI, 2008, p.31).
\end{abstract}

Desde sua origem, a tipografia estabeleceu forte ligação com aspectos econômicos, estéticos e técnicos. O processo de concepção e reprodução de tipos era, na maior parte das vezes, subdividido em duas funções específicas e complementares: a primeira baseada na concepção dos aspectos estéticos da produção e, a segunda, na modelagem individual de cada um dos punções [1] a serem utilizados durante a geração da matriz de uma fonte. O idealizador do projeto focava sua atenção, basicamente, no aprimoramento dos aspectos estéticos inerentes ao trabalho ou às questões comerciais da produção, uma vez que, de acordo com Cláudio Rocha (2002), detinha apenas parte da habilidade técnica necessária para realização das funções do processo produtivo.

A tecnologia tipográfica confere ao homem o primeiro meio de produção e acesso à informação em grande escala, algo até então restrito a poucos privilegiados. Sua criação caracterizou-se pela introdução técnica de processos associados que the justificam o caráter inovador: a adoção das matrizes metálicas que permitiram a fácil multiplicação dos caracteres tipográficos e do seu molde de fundição e a utilização da prensa. A composição tipográfica manual perdurou praticamente inalterada até fins do século XIX e, ainda hoje, pode ser encontrada em pleno funcionamento em pequenas gráficas. 
A utilização da cor na impressão tipográfica, ainda que localizada [2], marca o primeiro avanço significativo no processo com a edição de Saltério, considerado o primeiro livro impresso datado e assinado com essa nova tecnologia, produzido por Johann Furst e Peter Schöffer, no ano de 1457. Anteriormente, a cor era inserida manualmente após a impressão. Quatro anos mais tarde, outro salto qualitativo na tecnologia de impressão diz respeito à combinação da xilogravura aos tipos móveis, garantindo assim a produção da primeira obra impressa com recursos de ilustração. Destaque para a introdução da gravura em talha, nos anos de 1470, utilizando processo de gravura em relevo sobre chapa de metal. A imagem é gravada com buril e comprimida sobre o papel, que recebe a tinta então depositada sobre os entalhes, formando assim a imagem.

Passados quase três séculos do surgimento dos tipos móveis de Gutenberg e pouco se preocupavam os fundidores com a falta de uniformidade nas medidas de altura e corpo dos tipos que produziam. Nesse contexto, uma importante contribuição foi legada pelo tipógrafo francês Pierre-Simon Fournier ao estabelecer o ponto tipográfico, ou seja, a unidade de medida que serve para a determinação da força do corpo dos caracteres, equivalente a $0,350 \mathrm{~mm}$, alterada anos mais tarde por FrançoisAmbroise Didot para os $0,376 \mathrm{~mm}$.

Em fins do século XIX, em consequência de uma vida cotidiana cada vez mais acelerada e do crescente interesse público por número maior de conteúdos, impôs-se a necessidade de modificação no sistema tradicional de composição, naturalmente lento em sua operacionalização. Nesse contexto, em 1884, surge o linotipo, desenvolvido por Otmar Mergenthaler, que consiste em um sistema de composição de linhas completas a partir de matrizes metálicas selecionadas em um teclado semelhante a uma máquina de escrever. Ao toque de uma das teclas, a matriz respectiva é acionada passando a ocupar seu lugar na linha, ao lado das demais. Ao término de cada palavra, o linotipista [3] pressiona uma tecla que determina o espaçamento entre termos e assim sucessivamente até o final da linha. Formada esta, as matrizes são prensadas gerando molde que, fundido, gera a matriz de cada uma das linhas, facilitando a formação das galés [4] e o 
preparo (e eventuais reparos) das páginas. Inicialmente esse processo possibilitava apenas o uso de tipos com corpo pequeno para composição de textos, no entanto, a fundição de corpos maiores foi possível com o surgimento das máquinas "tituleiras" em meados do século $\mathrm{XX}$.

Por sua vez, à mesma época do linotipo, Tolbert Lanston apresenta a monotipo, sistema de composição onde o texto é também redigido em teclado, produzindo fita perfurada com os respectivos caracteres e alinhamento das linhas. A fundidora, comandada pela fita, seleciona a matriz correspondente a cada caractere por um sistema de ar comprimido e produz as linhas de composição em caracteres e espaços soltos como na composição manual, processo sensivelmente mais lento que o linotipo.

$\mathrm{O}$ início do século $\mathrm{XX}$ revoluciona os processos de impressão com o sistema offset, elaborado pelo tipógrafo Ira W. Rubel que teve grande repercussão mundial. A composição gravada em chapa de metal flexível é transferida para o papel por intermédio de um cilindro de borracha, revolucionando não apenas o processo de produção, mas também a criação gráfica e as potencialidades da comunicação visual enquanto meio de informação e pesquisa estética.

Embora os conceitos e a prática tipográfica tenham se ampliado muito além dos blocos de metal fundido, por meio dos novos modos de criação e produção, especialmente aqueles intermediados por ferramentas eletrônicas, a tipografia contemporânea ainda mantém, em suas terminologias, referências explícitas das práticas mecânicas. Um exemplo é o termo fonte, do latim fundere (fundir), aplicado para designar famílias de caracteres tipográficos. O mesmo ocorre com o termo tipo - bloco de metal fundido com o signo a ser impresso, associado a caracteres de um alfabeto. Conforme Isabella Perrota (2005, p. 31):

o uso da tecnologia permitiu o acesso às heranças tipográficas, gerando incontáveis interpretações da tipografia de todas as épocas. Este acesso ampliou o vocabulário do design e fomentou boas discussões sobre as relações com o passado. 
$\mathrm{O}$ advento da tipografia digital e o constante aperfeiçoamento dos softwares subsidia permanentes mudanças nesse cenário temático. Os tipos deixaram de ser objetos com propriedades físicas transformando-se em sequências de códigos binários (ROCHA, 2002). Essa mudança de paradigma gerou uma explosão de novos tipos, fruto do uso indiscriminado de programas de computador, desencadeando perda gradual na qualidade dos produtos desenvolvidos que, por vezes, não atendem às exigências mínimas no desenho de letras. É fato, porém, que as novas tecnologias estão cada vez mais presentes no cotidiano humano, principalmente, na expansão dos meios de informação e comunicação (GOMES, 2007), e como nos lembra Lúcia Santaella (2003, p.183):

\footnotetext{
Nas relações que se tecem, aliás inseparáveis, entre tecnologia e comunicação, a exigência de superação das avaliações extremadas se torna ainda mais premente, visto que compreender as transformações de ordem social e também psíquica que estão se operando na comunicação e na cultura sob impacto das novas tecnologias é uma tarefa que não pode ser negligenciada.
}

A consequência desse panorama é a existência, hoje, de considerável disputa de mercado em tipografia. O tipo digital deixou de ser uma ferramenta onerosa, restrita e especializada, e transformou-se em um objeto disponível aos profissionais gráficos e também amadores da área (NIEMEYER, 2003; CESAR, 2000). Por conseguinte, a inexorável desvalorização comercial de projetos tipográficos elaborados era previsível, gerando desinteresse gradual de novos designers a se aventurarem profissionalmente neste campo, oportunizando espaço para o desenvolvimento de produtos pouco fundamentados.

O profissional em tipografia expressa em seu trabalho sua visão e estilo, buscando renovação da linguagem visual e/ou a ruptura estética. Segundo Rocha (2002), a qualidade técnica de uma fonte digital é definida basicamente por dois fatores: o primeiro é a resolução, ou seja, adequação de cada desenho ao programa modular estabelecido no projeto, além da confirmação da individualidade de cada signo e grau de parentesco entre eles. O segundo é a inclusão de caracteres e sinais complementares de um 
alfabeto. A ausência desses quesitos em uma fonte pode comprometer sua qualidade e reduzir sua eficiência. De acordo com Perrota (2005, p. 26), "raramente as novas tipografias são autenticamente novas, mas criadas a partir da desconstrução e reconstrução de antigos alfabetos". Para se desenvolver uma tipografia completa, complexa e tecnicamente eficaz, fazse necessário estar atento a todo um conjunto de exigências. Porém, a tipografia não deve ser entendida restrita apenas a um sistema lógico de escrita, mas também como linguagem estética. $O$ design e o arranjo de tipos define objetivamente a identidade e o discurso de suas formas: é um desenho que se faz por meio das letras.

O aumento na oferta de novos produtos tipográficos pouco fundamentados, conforme já citado, demanda necessário desenvolvimento de estudos mais criteriosos acerca da adaptabilidade básica do desenho da letra em conformidade com o suporte no qual será aplicada, para que a transmissão da mensagem não seja comprometida. Assim sendo, prezar pelo aprimoramento técnico-conceitual e uso dos recursos tecnológicos, tornou-se imprescindível na expansão responsável e eficaz dos meios de comunicação e, consequentemente, da informação. Ressaltamos que no decorrer dos últimos séculos, as três funções básicas das artes gráficas, como bem descreve Richard Hollis (2001), sofreram poucas alterações quanto à sua aplicabilidade: 1. identificar; 2. informar e instruir; e 3. apresentar e promover, relacionados à determinada ideia ou produto.

De acordo com Lúcia Santaella (2003), a comunicação só é possível quando a mensagem, carregada de informação, é transportada de um ponto a outro, objetivando exercer alguma influência ou produzir alguma transformação no receptor. Essa mensagem só existe quando materializada em signos que devem estar, de alguma forma, codificados para serem capazes de informar. Toda informação precisa se corporificar em algo: a tipografia funciona, então, como canal nesse processo de trocas simbólicas.

Conclusões: (1) não há comunicação sem transmissão de uma informação; (2) não há informação que não esteja encarnada numa mensagem; (3) não há mensagens sem signos; (4) não pode haver transmissões de mensagens sem um canal que a transporte (SANTAELLA, 2003, p. 184). 
De maneira complementar, Coelho Netto (2007, p.129) ainda enfatiza:

\begin{abstract}
[...] a mudança no comportamento do receptor de uma mensagem depende do caráter de novo desta mensagem, de tal modo que se pode afirmar a existência da seguinte relação: quanto maior a taxa de novidade de uma mensagem, maior seu valor informativo, sendo maior a mudança de comportamento provocada.
\end{abstract}

A mensagem tipográfica se estabelece a partir da configuração que é dada a seus elementos compositivos. Enquanto linguagem visual, o que muda na tipografia são suas intenções e estratégias ao comunicar: quando necessário, torna-se "transparente" apenas para ser lida; em outros momentos, suas letras assumem aparência instigante, despertam ênfase para si e exigem atenção e interação do leitor. Portanto, transmite ideias, intenções, opiniões, personalidade e estilo, transformando-se em um produto cultural em plena sintonia com as transformações de uma época e modismos, como cita Steven Heller (2007, p. 182): "a tipografia, tal como comprimento das saias, varia conforme as tendências da moda". Donis A. Dondis (2007, p.131) descreve importante consideração:

\begin{abstract}
O conteúdo e a forma são componentes básicos, irredutíveis, de todos os meios [...], e, como é nossa principal preocupação aqui, das artes e ofícios visuais. $O$ conteúdo é fundamentalmente o que está sendo direta ou indiretamente expresso; é o caráter da informação, a mensagem. Na comunicação visual, porém, o conteúdo nunca está dissociado da forma. Muda sutilmente de um meio a outro e de um formato a outro, adaptando-se às circunstâncias de cada um.
\end{abstract}

Hoje, a possibilidade de se estabelecer conexões mais significativas entre o presente e o passado, diversifica e enriquece a produção tipográfica. O legado histórico da tipografia existe enquanto ferramenta de trabalho. Seu uso deve ser compreendido como conjunto de elementos sujeitos a constante evolução, inserido num contexto de contínuas mudanças culturais, tecnológicas e socioeconômicas (GRUSZYNSKI, 2008). Concluímos com Cláudio Ferlauto (2000, p. 12):

Nos dias de hoje, a tecnologia avançada permite que todos os alfabetos criados nos últimos quinhentos anos caibam em nossos computadores pessoais, digitalizados, virtuais, prontos 
para um uso facilitado e muito simples. Isso possibilitou o acesso às obras-primas de Bodoni e Garamond a um vasto público leigo de todas as idades e escolaridades.

\title{
Considerações finais
}

O processo de comunicação baseado em códigos visuais instituiu a concepção de alfabetos amplamente disseminados nas diversas culturas do planeta, garantindo ao indivíduo humano a possibilidade de entender e se fazer entendido por meio de elementos gráficos ordenadamente dispostos sobre determinado suporte. A escrita é o principal meio de informação e uma das mais relevantes características da espécie humana. Associada ao poder de leitura da palavra, a forma como esta é representada mostrou-se igualmente importante, explicitando íntima relação com estilo e, por conseguinte, com elementos e princípios das artes visuais e do prazer estético.

Nesse sentido, o ato de registro e comunicação de um texto incorpora não só a informação em si, mas também todo contexto plástico-visual decorrente de um momento histórico inerente a uma sociedade/cultura ou aquele associado, simplesmente, ao que se escreve. Cita Rocha (2002, p. 12):

\begin{abstract}
[...] o patrimônio cultural da humanidade preservado por meio da escrita não está restrito ao surgimento da tipografia e nesse sentido recua alguns milênios, quando pensamentos e fatos começaram a ser registrados por meio de ideogramas e signos fonéticos. Esses registros foram feitos com os mais variados instrumentos e sobre diferentes suportes. Os desenhos das letras produzidos por culturas e povos distintos continuam sendo estudados, recriados e reaproveitados como matériaprima para o design tipográfico.
\end{abstract}

No campo da imagem, a história é marcada por movimentos artísticos que influenciaram diretamente o processo de criação tipográfica, propondo sentidos visuais mais amplos e complexos. No século $X X$, essas interferências mostraram-se ainda mais significativas principalmente com a presença cada vez mais consolidada do design enquanto campo do conhecimento. Ainda que surgido em fins do séc. XIX, o Art Noveau perdurou nas primeiras décadas do século seguinte, exercendo importante 
influência na criação de letras a serem aplicadas em pôsteres, revistas, jornais e outros. Nesse período, a tipografia deixou de se dedicar apenas à difusão genérica de informações de forma padronizada e passou a exercer maior atratividade, por meio de suas formas elaboradas, curvilíneas e sinuosas. Por sua vez, o Cubismo demonstra novas técnicas de composição de imagens, com destaque às colagens e ao uso de letras estampadas (HULBURT, 2002). Dentro do contexto da revolução socialista, o Construtivismo marca uma arte graficamente simples, refletida na tipografia pela grande difusão de formas como círculos, quadrados, triângulos e linhas grossas, de nítidos cortes de ângulos (PASCHOAL, 2006). Já o Dadaísmo contesta e desmistifica valores e culturas, anunciando o elemento da desordem, a "descoordenação motora" (SILVA, 2005). Contrariamente, a Bauhaus, escola modernista de arte, design e arquitetura, favorece um design racional, no qual cada forma segue sua função, em busca da transmissão de mensagens da maneira mais rápida e eficiente possível, agregando à produção tipográfica a elaboração de formas claras, simples e racionalmente construídas.

Por meio desta breve leitura sobre a relevância de movimentos históricos no contexto tipográfico, é possível afirmar que a tipografia de hoje não será a mesma do amanhã. $O$ aprimoramento tecnológico somado às transformações sócio-culturais continuarão a provocar profundas mudanças no processo de concepção e reprodução de tipos. Seja no aprimoramento ou na ruptura, a herança tipográfica consubstanciará sempre a base de novos discursos.

Com o advento da tipografia digital as possibilidades discursivas e práticas ampliaram. Contudo, como afirma Bringhust (2005), as chamadas velhas tecnologias, livres de suas obrigações comerciais, ainda estão longe de morrer. O tipo de fundição, a monotipo, e a prensa continuarão coexistindo no cenário de criação como "importantes instrumentos artísticos, ao lado do pincel e do cinzel, da goiva e da caneta" (BRINGHUST, 2005, p. 157).

É diante desse cenário que novos desafios se configuram também no ensino acadêmico da tipografia. $O$ desenvolvimento de práticas 
metodológicas que refletem o contexto social e estabelecem novas frentes de comunicação com outras áreas do conhecimento, tais como sociologia, a teoria da comunicação, semântica, semiótica, computação e métodos de planejamento, será um desafio a ser enfrentado por aqueles que venham a se envolver com o exercício tipográfico. Para Weingart (2004, p. 77), "precisamos de personalidades que possam influenciar o desenvolvimento da tipografia com suas contribuições pessoais", de uma massa crítica flexível capaz de articular conhecimento especializado com as demandas da prática profissional.

\section{Notas de fim}

[1] Lâmina de metal com letras em relevo. Desse punção obtinha-se uma matriz de latão que se adaptava a uma estrutura ajustável que controlava a largura e a altura do tipo. Em um segundo momento, surgem os punções de aço que originam matrizes de cobre. O metal utilizado na fundição dos caracteres era uma liga de chumbo e antimônio e, mais tarde, estanho.

[2] O primeiro processo de impressão completo a cores, patenteado nos anos de 1710 por Jakob Le Blon, utilizava, inicialmente, chapas com sete cores. Posteriormente esse número foi reduzido para quatro: vermelho, amarelo, azul e, por vezes, o preto.

[3] Responsável técnico pelo manuseio do linotipo.

[4] Peça de madeira ou metal na qual o tipógrafo coloca a composição.

\section{Referências}

BAXTER, Mike. Projeto de produto: guia prático para o design de novos produtos. São Paulo: Edgar Blucker, 1998.

BRINGHURST, Robert. Elementos do estilo tipográfico. São Paulo: Cosac Naify, 2005.

CESAR, Newton. Direção de arte em propaganda. São Paulo: Editora Futura, 2000.

COELHO NETTO, J. Teixeira. Semiótica, informação e comunicação. São Paulo: Perspectiva, 2007.

DONDIS, Donis A. Sintaxe da linguagem visual. São Paulo: Martins Fontes, 2007.

FARIAS, Priscila L. Tipografia digital: o impacto das novas tecnologias. Rio de Janeiro: Editora 2AB, 2001. 
FERLAUTO, Cláudio. O tipo da gráfica e outros escritos. São Paulo: Cachorro Louco, 2000.

GOMES, Cilene. O universo da sociedade da comunicação e da informação: um sentido da história e uma problemática atual. Revista Tecnologia e Sociedade, Curitiba: Editora UTFPR, n. 4, $1^{\circ}$ semestre 2007, p. 53-75.

GRUSZYNSKI, Ana Cláudia. Design gráfico: do invisível ao ilegível. São Paulo: Rosari, 2008.

HELLER, Steven. Linguagens do design: compreendendo o design gráfico. São Paulo: Rosari, 2007.

HOLLIS, Richard. Design gráfico: uma história concisa. São Paulo: Martins Fontes, 2001.

HURLBURT, Allen. Layout: o design da página impressa. São Paulo: Nobel, 2002.

NIEMEYER, Lucy. Tipografia: uma apresentação. Rio de Janeiro: 2AB, 2003.

PASCHOAL, Larissa Bueno Junqueira. Pôster de cinema e construtivismo russo. Trabalho de Conclusão de Curso (Especialização em Comunicação Social/habilitação em Multimeios. Pontifícia Universidade Católica de São Paulo, São Paulo, 2006.

PERROTA, Isabella. Tipos e grafias. São Paulo: SENAC, 2005.

ROCHA, Cláudio. Projeto tipográfico: análise e produção de fontes digitais. São Paulo: Rosari, 2002.

SANTAELLA, Lúcia. Cultura das mídias. São Paulo: Experimento, 2003.

SILVA, Rafael Souza de. Discursos simbólicos da mídia. São Paulo: Editora Universitária Leopoldina, 2005.

WEINGART, Wolfgang. Como se pode fazer tipografia suíça? São Paulo: Rosari, 2004. 